\title{
Adherence to Anaphylaxis Guidelines: Real-World Data From the Emergency Department of a Tertiary Hospital
}

\author{
Ponce Guevara LV ${ }^{1,2}$, Laffond Yges E E,2,3, Gracia Bara MT1,2, Moreno Rodilla E1,2,3, Muñoz Bellido FJ',2,3, \\ Lázaro Sastre $\mathrm{M}^{1,2}$, Macías Iglesias $\mathrm{EM}^{1,2}$, de Arriba Méndez $\mathrm{S}^{1,2}$, Campanón Toro $\mathrm{MV}^{1,2}$, \\ Dávila Gónzalez |1,2,3
}

'Department of Allergy, University Hospital of Salamanca, Spain

${ }^{2}$ Biosanitary Institute of Salamanca, IBSAL, Salamanca, Spain

${ }^{3}$ Department of Biomedical and Diagnostic Sciences, University of Salamanca, Spain

J Investig Allergol Clin Immunol 2018; Vol. 28(4): 246-252

doi: $10.18176 /$ jiaci.0243

\begin{abstract}
Background: Few studies have evaluated adherence to anaphylaxis guidelines in emergency departments (EDs).

Objective: The objective of this study was to evaluate adherence to anaphylaxis guidelines in the ED of a tertiary hospital.

Methods: Medical records of patients attended in the ED of University Hospital of Salamanca, Spain were reviewed. Those patients fulfilling the anaphylaxis criteria proposed by the NIAID/FAAN were selected.

Results: During a 1-year period, we identified 89 patients (74 adults and 15 children). The anaphylactic reaction was moderate in $65 \%$ of adults, severe in 34\%, and very severe in $1 \%$. In children, all reactions were moderate. Fewer than half of the patients (42\%) received adrenaline in the ED; this was administered intramuscularly in only $19 \%$ of cases. As for the severity of the reaction, $65 \%$ of patients with moderate reactions and $42 \%$ with severe reactions were not treated with adrenaline. At discharge from the ED, an adrenaline autoinjector was recommended to only $5.6 \%$ of patients. Fifty-two percent of patients received a documented allergy referral (57\% adults vs $27 \%$ children, $P=.047), 29 \%$ instructions about avoidance of triggers (31\% adults vs $20 \%$ children, NS), and $51 \%$ written instructions for recognition of anaphylaxis warning signs ( $41 \%$ adults vs $100 \%$ children, $P<.001)$.

Conclusion: The results of the study show a large discrepancy between recommendations in guidelines and management of anaphylaxis in the ED. Additional training efforts are needed to improve the treatment of patients with anaphylactic reactions.
\end{abstract}

Key words: Anaphylaxis. Guidelines. Adrenaline.

\section{Resumen}

Antecedentes: Pocos estudios han evaluado el cumplimiento de las recomendaciones de las guías clínicas de anafilaxia en los servicios de urgencias.

Objetivo: El objetivo de este estudio fue conocer el cumplimiento de las guías de anafilaxia en el servicio de urgencias (SU) de un hospital terciario.

Métodos: Se revisaron los informes de los pacientes atendidos en el SU del Hospital Universitario de Salamanca durante un año y se seleccionaron los que cumplían los criterios de anafilaxia propuestos por el NIAID/FAAN.

Resultados: Se identificaron 89 pacientes, 74 adultos y 15 niños. El 65\% de los adultos presentó una reacción moderada, el 34\% grave y el $1 \%$ muy grave; en todos los niños la gravedad fue moderada. Menos de la mitad de los pacientes (42\%) fueron tratados con adrenalina, solo el $19 \%$ por vía intramuscular. El $65 \%$ de las reacciones moderadas y el $42 \%$ de las graves no recibieron adrenalina. Al alta, se recomendó un auto-inyector de adrenalina al 5,6\% de los pacientes, se remitió al Servicio de Alergia al 52\% (57\% adultos frente a $27 \%$ niños, $p=0,047$ ), se dieron indicaciones para evitar posibles desencadenantes al $29 \%$ (31\% adultos frente a $20 \%$ niños, $p=.5$ ) e instrucciones para reconocer los signos de alarma de una reacción anafiláctica al 51\% (41\% adultos frente a 100\% niños, P<0,001). Conclusión: Los resultados del estudio muestran importantes discrepancias entre las recomendaciones de las guías clínicas y el manejo de la anafilaxia en un SU hospitalario. Es necesario un mayor esfuerzo en educación para mejorar el tratamiento de los pacientes con anafilaxia.

Palabras clave: Anafilaxia. Guías clínicas. Adrenalina. 


\section{Introduction}

Anaphylaxis is defined as a serious, potentially fatal allergic reaction of sudden onset [1-3]. Diagnosis of anaphylaxis can be difficult because the reaction can mimic other, more common diseases. In addition, rapid recognition of anaphylaxis is essential for prompt and adequate treatment. This is particularly important for physicians working in emergency services. Anaphylaxis guidelines recommend intramuscular adrenaline as first-line treatment [1-3]. The guidelines also recommend self-treatment measures, such as adrenaline auto-injectors and written instructions to patients and caregivers for the early recognition of symptoms and avoidance of possible triggers. In addition, follow-up by a specialist is essential to investigate possible triggers, perform a comprehensive risk assessment, and prevent future episodes. To date, few studies have evaluated adherence to anaphylaxis guidelines in the emergency department (ED). These studies have confirmed major discrepancies with the recommendations on treatment and follow-up [4-7]. The objective of this study was to evaluate management of anaphylaxis and adherence of clinicians to recommendations on anaphylaxis in guidelines. We conducted a 1-year study in children and adults who presented at the ED of a tertiary hospital and were diagnosed with anaphylaxis.

\section{Methods}

\subsection{Patients}

Ours was a single-center study. The medical records of patients attended in the ED of University Hospital of Salamanca, Spain, from September 1, 2011 to August 31, 2012 were reviewed the following working day. Anaphylactic reactions were identified by reviewing the medical records of patients who were discharged with any of the following diagnostic codes of the International Classification of Disease, Ninth Revision: anaphylactic shock caused by food (995.60995.69); other anaphylactic shock (995.0); angioneurotic edema (995.1); urticaria (708); allergic urticaria (708.0); idiopathic urticaria (708.1); an unspecified adverse effect caused by the correct administration of a drug, medicinal, or biologic substance (995.2); an unspecified allergic reaction (995.3); other specified urticaria (708.8); unspecified urticaria (708.9); edema of larynx (478.6); edema of pharynx or nasopharynx (478.25); and the toxic effect of venom (989.5).

Those patients fulfilling the anaphylaxis criteria proposed by the National Institute of Allergy and Infectious Diseases/ Food Allergy and Anaphylaxis Network (NIAID/FAAN) were selected [8]. In addition, we telephoned all of the patients, who agreed to participate. Data were confirmed and missing data completed when possible. The study was authorized by the local ethics committee (PI4505/2011). We considered pediatric age to be between 0 and 14 years.

We recorded demographic data, symptoms, physical examination findings, suspected triggers, and ED management. In addition, at discharge, we recorded prescription of selfinjectable adrenaline, other prescriptions, provision of an action plan (or not), and referral to the allergy department.

\subsection{Definition and Severity of Anaphylaxis}

Patients were considered to have anaphylaxis when their condition met the clinical criteria established by the NIAID/FAAN [8], as follows: (i) Involvement of skin and/or mucosal tissue and with respiratory compromise or signs of cardiovascular dysfunction or hypotension; (ii) Involvement of 2 or more systems (skin and/or mucosal tissue, respiratory, cardiovascular, and gastrointestinal) after recent exposure to a likely allergen; or (iii) Signs of cardiovascular dysfunction after exposure to a known allergen.

Anaphylaxis was classified into 5 grades according to severity following the classification of Ring and Behrendt [9]. An episode was defined as severe if the patient presented arterial oxygen saturation $\leq 92 \%$, arterial hypotension ( systolic arterial tension $<90 \mathrm{mmHg}$ ), and/or neurologic involvement.

\subsection{Data Analysis}

Data were collected and analyzed using SPSS 19.0 (IBM Corp). Continuous parametric data are presented as mean (SD), and the exact $95 \%$ confidence interval (CI) is indicated. Nonparametric continuous data are represented as median (IQR). ANOVA or ANOVA on ranks was used to determine statistical significance between continuous variables; dichotomous variables were analyzed using the $\chi^{2}$ and Fisher exact test. Statistical significance was set at $P<.05$.

\section{Results}

\subsection{Patient Characteristics}

A total of 148712 patients were attended in the ED during the observation period. The initial screen identified 1575 records of potential anaphylaxis. A meticulous review of these medical records identified 89 patients fulfilling the NIAID/FAAN criteria for the diagnosis of anaphylaxis, with an

Table 1. Demographic Characteristics

\begin{tabular}{lcc}
\hline & No. & $\%$ \\
\hline Global sample & 89 & 100 \\
Sex & & \\
$\quad$ Male & 45 & 50.60 \\
$\quad$ Female & 44 & 49.40 \\
Age & & \\
$<14$ y (mean age $5.4[3.13]$ y) & 15 & 16.85 \\
$\quad$ Males & 11 & 73.33 \\
Females & 4 & 26.66 \\
$>14$ y (mean age $47.85[17.67]$ y) & 74 & 83.14 \\
$\quad$ Males & 34 & 45.94 \\
$\quad$ Females & 40 & 54.05 \\
Personal history of allergy & 36 & 40.44 \\
$\quad$ Adults & 26 & 35.13 \\
$\quad$ Children & 10 & 66.66 \\
Previous episodes of anaphylaxis & 10 & 11.23 \\
$\quad$ Adults & 8 & 10.81 \\
$\quad$ Children & 2 & 13.33 \\
$\quad$
\end{tabular}


incidence of $0.06 \%$ in relation to the total number of patients attended in the ED. Data for the anaphylactic reaction were recorded from all patients. In addition, we telephoned all patients to collect further data. Overall, 74 patients $(83 \%)$ were adults and 15 patients $(17 \%)$ were children, with a slight predominance of males $(51 \%)$ in the overall sample, a predominance of females in the adults (54\%), and a predominance of males in children $(73 \%)$. These differences did not reach statistical significance. Mean age for the whole sample was 41 (22.7) years (range, 1 to 86 years). Mean age was 5.4 (3.1) years in children (Table 1).

Thirty-six (40\%) patients had a personal history of allergic diseases, distributed as follows: food allergy, 50\%; asthma, $16.7 \%$; drug allergy, $16.7 \%$; rhinoconjunctivitis, $2.8 \%$; Anisakis simplex allergy, 2.8\%; latex allergy, 2.8\%; urticaria, $2.8 \%$; and atopic dermatitis, $2.8 \%$. The percentage of patients reporting a history of allergic diseases was significantly higher in children than adults (67\% vs $35 \%$, respectively, $P=.023)$. Of the 89 patients, $10(11 \%)$ reported a previous anaphylactic event.

According to the ED medical report, most reactions were triggered by food, both in adults and children (43\%), followed by drugs (34\%), and unknown causes (13.5\%). One reaction was associated with the administration of specific subcutaneous immunotherapy, and 8 reactions were due to hymenoptera sting.

\subsection{Clinical Manifestations}

All patients had cutaneous symptoms during the anaphylactic episode. Seventy-two patients $(81 \%)$ presented respiratory symptoms, and 28 patients $(31.5 \%)$ complained of gastrointestinal symptoms. Twenty-six patients (29\%) experienced hypotension in the ED. All patients who had hypotension were adults $(P=.006)$ (Table 2$)$.

The mean duration of symptoms was 103 minutes (10-480 minutes). Only 2 adult patients (2.2\%) experienced a biphasic reaction.

Sixty-three $(71 \%)$ had a moderate anaphylactic reaction, $25(28 \%)$ had a severe reaction, and $1(1 \%)$ had a very severe reaction. In the case of pediatric patients, the reactions were moderate in $100 \%$. In comparison, 48 adult patients $(65 \%)$ had moderate anaphylaxis $(P=.024)$.
Table 2. Presentation of Symptoms During the Anaphylactic Episode

\begin{tabular}{lcccc}
\hline Symptoms & $\begin{array}{c}\text { Adults } \\
\text { No. }(\%)\end{array}$ & $\begin{array}{c}\text { Children } \\
(\%)\end{array}$ & $P$ Value & $\begin{array}{c}\text { Total } \\
\text { No. }(\%)\end{array}$ \\
\hline Skin & 74 & 15 & - & 89 \\
& $(100)$ & $(100)$ & & $(100)$ \\
Gastrointestinal & 24 & 4 & NS & 28 \\
& $(32.43)$ & $(26.66)$ & & $(31.46)$ \\
Respiratory & 58 & 14 & NS & 72 \\
Cardiovascular & $(78.37)$ & $(93.33)$ & & $(80.89)$ \\
& $(35.13)$ & 0 & .006 & 26 \\
& & & & $(29.21)$ \\
\hline
\end{tabular}

Only 6 patients (7\%) underwent determination of tryptase during the episode; all 6 were adults.

\subsection{Pharmacological Treatment Received in the Emergency Department}

\subsubsection{Frequency of administration of adrenaline}

Of the 89 patients, only 37 (42\%) were treated with adrenaline; of these, 31 were adults (42\%) and $6(40 \%)$ children (Table 3).

In relation to the severity of the reaction, adrenaline was administered in $35 \%$ of moderate anaphylactic reactions and in $58 \%$ of severe and very severe reactions. Although this difference was not statistically significant $(P=.07)$, there was a trend toward using adrenaline in the more severe cases.

In the group of adult patients who received adrenaline, $68 \%$ presented respiratory symptoms, 32\% gastrointestinal symptoms, and 48\% hypotension. Therefore, respiratory symptoms were the clinical manifestation that most frequently led to administration of adrenaline in both children and adults. Although hypotension was not the most frequent cause for administration of adrenaline, a higher percentage of patients with hypotension received adrenaline (58\%) than patients with respiratory manifestations $(37.5 \%)$ or digestive manifestations (39\%). All the children who received adrenaline experienced respiratory symptoms. None of them presented hypotension.

Table 3. Treatment Administered in the Emergency Department During the Anaphylactic Episode

\begin{tabular}{|c|c|c|c|c|}
\hline & Adults $n=74(\%)$ & Children $\mathrm{n}=15(\%)$ & $P$ Value & Total $\mathrm{N}=89(5 \%)$ \\
\hline Adrenaline & $31(41.89)$ & $6(40)$ & NS & $37(41.57)$ \\
\hline Intramuscular ${ }^{\mathrm{a}}$ & $4(12.90)$ & $3(50)$ & .068 & $7(18.91)$ \\
\hline Subcutaneous $^{\mathrm{a}}$ & $26(83.87)$ & $3(50)$ & .10 & $29(78.37)$ \\
\hline Intravenous $^{\mathrm{a}}$ & $1(3.22)$ & 0 & - & $1(2.7)$ \\
\hline \multicolumn{5}{|c|}{ Administration of adrenaline according to symptoms } \\
\hline Respiratory ${ }^{\mathrm{a}}$ & $21(67.74)$ & $6(100)$ & NS & $27(72.97)$ \\
\hline Gastrointestinal $^{\mathrm{a}}$ & $10(32.25)$ & $1(16.66)$ & NS & $11(29.72)$ \\
\hline Hypotension $^{\mathrm{a}}$ & $15(48.38)$ & 0 & - & $15(40.54)$ \\
\hline Corticosteroids & $64(86.48)$ & $12(80)$ & NS & $76(85.39)$ \\
\hline $\mathrm{H}_{1}$-antihistamines & $65(87.83)$ & $13(86.66)$ & NS & $78(87.64)$ \\
\hline
\end{tabular}

apercentage refers only to patients treated with adrenaline. 


\subsubsection{Dose and route of administration of adrenaline}

Thirty of 37 patients $(81 \%)$ received a single dose of adrenaline. Of these, $21(70 \%)$ had a moderate reaction, $8(27 \%)$ a severe reaction, and only $1(3 \%)$ a very severe anaphylactic reaction (this patient was subsequently transferred to the intensive care unit, where he received intravenous adrenaline). Seven patients (19\%) received more than 1 dose of adrenaline: $6(86 \%)$ had severe reactions and $1(14 \%)$ had a moderate reaction. Thus, patients with severe anaphylaxis received a significantly higher number of doses of adrenaline than patients with moderate anaphylaxis $(27 \%$ vs $86 \%, P=.01$ ).

Adrenaline was administered subcutaneously in $78 \%$ of patients and intramuscularly in $19 \%$. Only 1 patient received a single dose of intravenous adrenaline (3\%). Half of the pediatric patients received subcutaneous adrenaline and the other half intramuscular adrenaline (Table 3).

\subsection{3. $\mathrm{H}_{1}$ antihistamines and corticosteroids}

Most patients were treated with $\mathrm{H}_{1}$ antihistamines $(88 \%)$ and corticosteroids $(85 \%)$ regardless of the severity of the reaction. No significant differences were observed in relation to age.

\subsubsection{Other treatments}

Despite the high frequency of respiratory symptoms, only $21 \%$ of patients were treated with supplemental oxygen. Other treatments administered included $\beta_{2}$-agonist nebulization $(14 \%)$, intravenous fluids ( $45 \%)$, and ranitidine (32\%).

\subsubsection{Management at discharge}

Nearly all patients $(99 \%)$ with anaphylactic reactions were discharged home. Only 1 patient was hospitalized in the intensive care unit. The minimum stay in the ED was 30 minutes, and the maximum was 900 minutes, with an average of 180 minutes. A pharmacological treatment was prescribed at discharge in 86 patients $(97 \%$ ) (Table 4).

\subsubsection{Prescription for adrenaline auto-injector}

In the adult population, an adrenaline auto-injector was recommended at discharge to only 5 patients $(5.6 \%)$. No pediatric patients were prescribed adrenaline at discharge.

\subsection{7. $\mathrm{H}_{1}$-antihistamines and corticosteroids}

A combination of antihistamines and corticosteroids was prescribed for most children $(60 \%)$. For adults, the most common prescription was $\mathrm{H}_{1}$-antihistamines (49\%).

\subsubsection{Referral to an allergist}

At discharge from the ED, $52 \%$ of patients were referred to an allergist. Of these, 42 were adults (57\%) and 4 were children $(27 \%)(P=.047)$ (Table 4).

\subsubsection{Written instructions for avoidance of triggers and identifying symptoms of a new reaction}

Only 48 patients $(54 \%)$ received written instructions for avoidance of suspected triggers or recognition of anaphylaxis symptoms. No differences were found between children and adults with respect to recommendations for trigger avoidance, although $100 \%$ of children were instructed to recognize the warning symptoms of anaphylaxis compared with $41 \%$ of adults $(P<.001)$ (Table 4$)$.

\section{Discussion}

We analyzed the management of anaphylaxis in 89 patients treated for an episode of anaphylaxis in the ED of a tertiary hospital. The World Health Organization classifies adrenaline as an essential medication for the treatment of anaphylaxis [1] because it has life-saving vasoconstrictor effects in most organ systems (except skeletal muscle). Adrenaline also prevents and alleviates airway obstruction caused by mucosal edema and relieves hypotension and shock [10-11]. However, there is a clear discrepancy between the information provided by guidelines on the management of anaphylaxis and the actual use of adrenaline as a first-line drug. In our study, adrenaline

Table 4. Management at Discharge

\begin{tabular}{lcccc}
\hline & $\begin{array}{c}\text { Adults } \mathrm{n}=74, \\
\text { No. (\%) }\end{array}$ & $\begin{array}{c}\text { Children } \mathrm{n}=15, \\
\text { No. (\%) }\end{array}$ & $P$ Value & $\begin{array}{c}\text { Total N=89, } \\
\text { No. (\%) }\end{array}$ \\
\hline $\begin{array}{l}\text { Adrenaline auto-injector + } \\
\mathrm{H}_{1} \text {-antihistamines + corticosteroids }\end{array}$ & $4(5.40)$ & 0 & - & $4(4.49)$ \\
Adrenaline auto-injector & $1(1.35)$ & 0 & - & $1(1.12)$ \\
$\mathrm{H}_{1}$-antihistamines & $36(48.64)$ & $5(33.30)$ & $\mathrm{NS}$ & $41(46.06)$ \\
Corticosteroids & $3(4.05)$ & 0 & - & $3(3.37)$ \\
$\mathrm{H}_{1}$-antihistamines + corticosteroids & $28(37.83)$ & $9(60)$ & .066 & $37(41.57)$ \\
No medication & $2(2.70)$ & $1(6.66)$ & $\mathrm{NS}$ & $3(3.37)$ \\
Referral to allergist & $42(56.75)$ & $4(26.66)$ & .047 & $46(51.68)$ \\
Avoidance of suggested triggers & $23(31.08)$ & $3(20.00)$ & $\mathrm{NS}$ & $26(29.21)$ \\
Recognition of alarm symptoms & $30(40.54)$ & $15(100)$ & $<.001$ & $45(50.56)$ \\
\hline
\end{tabular}


was administered to only $42 \%$ of the population, clearly indicating that there is a deficit in the treatment of this disease, as described in several studies [4-6,12-14]. Huang et al [15] included only patients younger than 18 years and found that $79 \%$ had received adrenaline in the ED. The authors reported that this high percentage could be due to the fact that the pediatric emergency department was affiliated to an allergy service. However, in other studies, adrenaline was much less frequently used. Helbing et al [16] reported that adrenaline was administered to $47.9 \%$ of patients. Orhan et al [17] found that only $32.2 \%$ of their patients received adrenaline as treatment for anaphylaxis. Beyer et al [18] also found a low percentage of use of adrenaline in the ED in Berlin, Germany, where it was used in only $22.7 \%$ of cases. In an observational study of patients aged more than 15 years attended at the ED of a tertiary hospital in Spain, Alvarez-Perea et al [19] found that only $40 \%$ of patients received adrenaline, which was administered more frequently when the ED physician diagnosed anaphylaxis, regardless of severity.

Conversely, Baalmann et al [20] conducted an observational study of patients treated in ED for anaphylaxis. Questionnaires and electronic health records were retrospectively reviewed by 2 board-certified allergists-immunologists, who considered that the treatment of the reaction had been appropriate in $98 \%$ of cases, although more than $60 \%$ of anaphylaxis patients did not receive adrenaline [20]. In our study, $58 \%$ of the patients did not receive adrenaline; however, when only severe reactions were considered, this percentage fell to $42 \%$. It is our understanding that all of these patients should have received adrenaline as a part of their treatment. Moreover, although the need for adrenaline in patients presenting moderate reactions is open to debate, it should be taken into account that it is not possible to predict the clinical picture of a patient who goes to the emergency department with an anaphylactic reaction and that these reactions progress rapidly and are potentially life-threatening.

Simons et al [21,22] clearly demonstrated the superiority of the absorption of adrenaline injected intramuscularly into the thigh. In our study, $78 \%$ of adrenaline administered in the ED was by the subcutaneous route, with only in $19 \%$ of cases administered intramuscularly. On the contrary, Alvarez-Perea et al [23] found that the intramuscular route was used in $96 \%$ of children with anaphylaxis who received adrenaline [23].

Taken together, these data mean that clinicians require further training on administration of adrenaline in anaphylaxis.

Guidelines also recommend administration of high-flow oxygen by facemask to all patients with anaphylaxis. In our study, only $21 \%$ of patients received oxygen, despite the fact that $81 \%$ presented respiratory manifestations. However, we found that $\mathrm{H}_{1}$-antihistamines and corticosteroids were the most frequently used drugs in the treatment of anaphylaxis in the ED ( $88 \%$ and $85.4 \%$, respectively). These results are similar to those found in other studies [4-6,12,15,18,24]. In most medical centers, the main drugs used to treat anaphylaxis regardless of the severity of the reaction are antihistamines and corticosteroids, although there are no placebo-controlled trials that support their effectiveness [1].

The WAO Anaphylaxis Guidelines state that patients must remain under observation in a medically supervised setting after improvement. The duration of monitoring should be individualized: at least 4 hours for patients with moderate anaphylaxis, and up to 8-10 hours or longer for patients with severe or protracted anaphylaxis. The average stay in the ED for the patients of our study was 3 hours (30-900 minutes). This figure refers to the total duration of emergency care, and not only the observation time after improvement, thus implying a much shorter observation time than recommended.

In addition, the guidelines emphasize the prevention and treatment of new anaphylactic episodes at discharge from hospital, with particular emphasis on prescription of adrenaline auto-injectors [1-3]. In our study, an adrenaline auto-injector was prescribed in the ED to only $6 \%$ of patients, all of whom were adults. Prescription of an adrenaline auto-injector and the number prescribed to an individual patient are controversial issues [25]. In our opinion, an adrenaline auto-injector should be prescribed in the ED at least to patients with a history of previous anaphylactic reactions and to all patients with severe reactions. In other studies, the rates of prescription of adrenaline varied between $8 \%$ and $63 \%$ [12,15,24,26-28].

Guidelines also recommend that an emergency action plan should be drawn up and personalized with recommendations for avoiding suggested triggers and how to recognize the warning signs. In our series, $54 \%$ of patients received these recommendations. All children and $41 \%$ of adults were instructed how to recognize warning signs, but only $29 \%$ of all patients were advised to avoid the suspected triggers.

In addition, guidelines recommend referring patients with anaphylaxis treated in the ED to an allergist for follow-up. In our study, $52 \%$ of patients were referred to the allergy department. Interestingly, only $27 \%$ of children were referred. This is in agreement with other authors, such as Rudders et al [27] and Banerji et al [24], who reported that only $18 \%$ of adults and $22 \%$ of children were referred from the ED for specialized assessment. Taken together, these data show the need to train and update emergency physicians in the importance of the prevention and treatment of a new episode, as anaphylaxis is a potentially deadly disease.

Consistent with other studies in this area [19,29], our study is limited by the fact that it was conducted in a single center and with a short observation period. Furthermore, since the incidence of anaphylaxis is low, the number of patients included, especially children, is small. In addition, some cases of anaphylaxis may not have been included owing to the identification method used. The lack of appropriate codes in the International Classification of Diseases, Ninth Revision makes this classification insufficient for identification of all anaphylactic reactions, particularly when only codes specifically indicating anaphylaxis are used [30-31]. The combination of several codes and the subsequent evaluation by an allergy specialist provides better results [15,32,33]. Finally, the lack of agreement in the main anaphylaxis guidelines (Galaxia, EAACI, WAO, AAAAI/ACAAI) regarding specific aspects of the management of patients with anaphylaxis could hamper studies that evaluate adherence of clinicians to recommendations.

In summary, we analyzed management of patients and adherence to anaphylaxis guidelines in the ED of a tertiary hospital. Adherence to recommendations was poor, with less than half of the patients treated with adrenaline. Furthermore, adrenaline was subcutaneously administered in most cases. In 
addition, about $50 \%$ of patients were referred to the allergist and were given a written action plan, although only $6 \%$ received a prescription for adrenaline auto-injectors. Taken together, these data reveal the need for a further and continuous effort for the implementation of guidelines for the management of anaphylaxis.

\section{Funding}

The authors declare that no funding was received for the present study.

\section{Conflicts of Interest}

The authors declare that they have no conflicts of interest.

\section{References}

1. Simons FE, Ardusso LR, Bilò MB, El-Gamal YM, Ledford DK, Ring J, et al. World allergy organization guidelines for the assessment and management of anaphylaxis. World Allergy Organ J. 2011 Feb;4(2):13-37.

2. Lieberman P, Nicklas RA, Oppenheimer J, Kemp SF, Lang DM, Bernstein DI, et al. The diagnosis and management of anaphylaxis practice parameter: 2010 update. J Allergy Clin Immunol. 2010 Sep;126(3):477-80.

3. Cardona Dahl V; Grupo de trabajo de la Guía GALAXIA de actuación en anafilaxia. [Guideline for the management of anaphylaxis]. Med Clin (Barc). 2011 Mar 26;136(8):349-55.

4. Grabenhenrich L, Hompes $S$, Gough $H$, Ruëff $F$, Scherer $K$, Pföhler C, Treudler $\mathrm{R}$, et al. Implementation of anaphylaxis management guidelines: a register-based study. PLoS One. 2012;7(5):e35778

5. Murad A, Katelaris CH. Anaphylaxis audit in a busy metropolitan Emergency Department: a review of real life management compared to best practice. Asia Pac Allergy. 2016 Jan;6(1):29-34.

6. Russell WS, Farrar JR, Nowak R, Hays DP, Schmitz N, Wood $J$, et al. Evaluating the management of anaphylaxis in US emergency departments: Guidelines vs. practice. World J Emerg Med. 2013;4(2):98-106.

7. Landsman-Blumberg PB, Wei W, Douglas D, Smith DM, Clark S, Camargo CA Jr. Concordance with recommended post discharge care guidelines among children with food-induced anaphylaxis. J Pediatr. 2014 Jun;164(6):1444-8.

8. Campbell RL, Hagan JB, Manivannan V, Decker WW, Kanthala $A R$, Bellolio MF, et al. Evaluation of national institute of allergy and infectious diseases/food allergy and anaphylaxis network criteria for the diagnosis of anaphylaxis in emergency department patients. J Allergy Clin Immunol. 2012 Mar; 129(3):748-52.

9. Ring J, Behrendt H. Anaphylaxis and anaphylactoid reactions. Classification and pathophysiology. Clin Rev Allergy Immunol. 1999;17(4):387-99.

10. Simons KJ, Simons FE. Epinephrine and its use in anaphylaxis: current issues. Curr Opin Allergy Clin Immunol. 2010;10(4):354-61

11. Kemp SF, Lockey RF, Simons FE. Epinephrine: the drug of choice for anaphylaxis. A statement of the World Allergy Organization. Allergy. 2008;63(8):1061-70.
12. Serbes M, Can D, Atlihan F, Günay I, Asilsoy S, Altinöz S, et al. Common features of anaphylaxis in children. Allergol Immunopathol (Madr). 2013 Jul-Aug;41(4):255-60.

13. Neugut Al, Ghatak AT, Miller RL. Anaphylaxis in the United States: an investigation into its epidemiology. Arch Intern Med. 2001;161(1):15-21

14. Arroabarren E, Lasa EM, Olaciregui I, Sarasqueta C, Muñoz JA, Pérez-Yarza EG. Abstract Improving anaphylaxis management in a pediatric emergency department. Pediatr Allergy Immunol. 2011;22(7):708-14.

15. Huang F, Chawla K, Jarvinen KM, Nowak-Węgrzyn A. Anaphylaxis in a New York City pediatric emergency department: triggers, treatments, and outcomes. J Allergy Clin Immunol. 2012;129(1):162-8.

16. Helbling A, Hurni T, Mueller UR, Pichler WJ. Incidence of anaphylaxis with circulatory symptoms: a study over a 3-year period comprising 940,000 inhabitants of the Swiss Canton Bern. Clin Exp Allergy. 2004;34(2):285-90.

17. Orhan F, Canitez Y, Bakirtas A, Yilmaz O, Boz AB, Can D, Kuyucu, et al. Anaphylaxis in Turkish children: a multi-centre, retrospective, case study. Clin Exp Allergy. 2011;41(12):1767-76.

18. Beyer K, Eckermann O, Hompes S. Anaphylaxis in an emergency setting - elicitors, therapy and incidence of severe allergic reactions. Allergy. 2012;67(11):1451-6.

19. Alvarez-Perea A, Tomás-Pérez M, Martínez-Lezcano P, Marco G, Pérez D, Zubeldia JM, el al. Anaphylaxis in Adolescent/ Adult Patients Treated in the Emergency Department: Differences Between Initial Impressions and the Definitive Diagnosis. J Invest Allergol Clin Immunol. 2015; 25(4):28894

20. Baalmann DV, Hagan JB, Li JTC, Hess EP, Campbell RL. Appropriateness of epinephrine use in ED patients with anaphylaxis. Am J Emerg Med. 2016;34:174-9.

21. Simons FE, Gu X, Simons KJ. Epinephrine absorption in adults: intramuscular versus subcutaneous injection. J Allergy Clin Immunol. 2001;108(5):871-3.

22. Simons FE, Roberts JR, Gu X, Simons KJ. Abstract Epinephrine absorption in children with a history of anaphylaxis. J Allergy Clin Immunol. 1998;101(1 Pt 1):33-7.

23. Alvarez-Perea A, Ameiro B, Morales C, Zambrano G, Rodríguez A, Guzmán M, et al. Anaphylaxis in the Pediatric Emergency Department: Analysis of 133 Cases After an Allergy Workup. J Allergy Clin Immunol Pract. 2017;5:125663.

24. Banerji A, Rudders SA, Corel B. Repeat epinephrine treatments for food-related allergic reactions that present to the emergency department. Allergy Asthma Proc. 2010;31(4):30816.

25 Muraro A, Roberts G, Worm M, Bilò MB, Brockow K, FernándezRivas $M$, et al. Anaphylaxis: guidelines from the European Academy of Allergy and Clinical Immunology. Allergy. 2014 Aug;69(8):1026-45.

26. Gelincik A, Demirturk M, Yilmaz E, Ertek B, Erdogdu $D_{\text {, }}$ Çolakoğlu B, et al. Anaphylaxis in a tertiary adult allergy clinic: a retrospective review of 516 patients. Ann Allergy Asthma Immunol. 2013;110(2):96-100.

27. Rudders SA, Banerji A, Katzman DP, Clark S, Camargo CA Jr. Abstract Multiple epinephrine doses for stinging insect hypersensitivity reactions treated in the emergency 
department. Ann Allergy Asthma Immunol. 2010;105(1):8593.

28. Oren E, Banerji A, Clark S, Camargo CA Jr. Food-induced anaphylaxis and repeated epinephrine treatments. Ann Allergy Asthma Immunol. 2007;99(5):429-32.

29. Moro M, Tejedor MA, Esteban J, Rosado A, Vila C. Incidence of Anaphylaxis and Subtypes of Anaphylaxis in a General Hospital Emergency Department. J Investig Allergol Clin Immunol. 2011;21(2):142-9.

30. Klein JS, Yocum MW. Underreporting of anaphylaxis in a community emergency room. J Allergy Clin Immunol. 1995; $95: 637-8$.

31. Trojan T, Ma Y, Khan DA. Anaphylaxis Identification Using Direct and Combined ICD-9 Methods. J Allergy Clin Immunol. 2013;131.

32. Schneider G, Kachroo S, Jones N, Crean S, Rotella P, Avetisyan $\mathrm{R}$, Reynolds MW. A systematic review of validated methods for identifying anaphylaxis, including anaphylactic shock and angioneurotic edema, using administrative and claims data. Pharmacoepidemiol Drug Saf. 2012; 21(S1):240-7.
33. Nieto $A$, Tejedor-Alonso MA, Farias-Aquino $E$, Moro $M$, Rosado A, Gonzalez-Moreno A, et al. Clinical Profile of Patients With Severe Anaphylaxis Hospitalized in the Spanish Hospital System: 1997-2011. J Investig Allergol Clin Immunol. 2017;27(2):111-26. Manuscript received July 21, 2017; accepted for
publication February 16, 2018.

\section{Elena Laffond Yges}

Servicio de Alergia Hospital Universitario de Salamanca

Paseo de San Vicente, 58-182

37007 Salamanca, Spain

E-mail: laffond@usal.es; mlaffond@saludcastillayleon.es 